\title{
TAMAN HIBURAN TEMATIK DUNIA ANJING DI JAKARTA
}

\author{
Gracia $^{1)}$, Stephanus Huwae ${ }^{2)}$ \\ 1) Program Studi S1 Arsitektur, Fakultas Teknik, Universitas Tarumanagara, gracia.ta@stu.untar.ac.id \\ 2) Program Studi S1 Arsitektur, Fakultas Teknik, Universitas Tarumanagara, ituthuwae@gmail.com
}

\begin{abstract}
Abstrak
Kehidupan di tengah kota metropolis melahirkan sebuah iklim hedonisme, dimana setiap orangnya merasa bahagia dengan hidup berfoya-foya dan komsuntif. Banyak orang yang secara tidak sadar menjadikan hedonisme sebagai tujuan hidup, seperti bekerja tanpa henti demi membeli rumah mewah. Banyak orang tidak sadar bahwa kesenangan mereka akan rumah mewah hanyalah kesenangan yang sementara. Begitu mendapatkan rumah mewah, harus kembali bekerja untuk memenuhi kebutuhan rumah mewah tersebut yang juga mahal, seperti pajak dan perawatannya. Keinginan dalam iklim hedonisme akan terus bertambah sehingga dikatakan kebahagiaan yang di dapat hanyalah kebahagiaan sementara. Theme park dapat diartikan sebagai "realitas pengganti realitas", yaitu suatu usaha untuk mewujudkan impian. Segalanya adalah mungkin, hingga pada akhirnya theme park mengkriteriakan faktor pengunjung yang bukan sebagai penonton melainkan juga sebagai pemain. Hewan menjadi daya tarik yang sangat diminati pada era ini karena pengunjung dapat berinteraksi langsung dengan objek wisata yang hidup atau dapat dikatakan "hubungan dua arah". Anjing merupakan hewan yang paling dekat dan bisa berinteraksi langsung dengan manusia secara aman dan menyenangkan. Anjing merupakan mahkluk sosial seperti halnya manusia. Anjing memiliki posisi unik dalam hubungannya dengan manusia. Kesetiaan dan pengabdian yang ditunjukkan anjing sangat mirip dengan konsep manusia tentang cinta dan persahabatan. Kedekatan anjing dan manusia menjadikan anjing bisa dilatih, diajak bermain, tinggal bersama manusia serta bersosialiasi secara intens dengan manusia, anjing maupun hewan lain.
\end{abstract}

Kata kunci: hedonisme, interaksi langsung, realitas

\begin{abstract}
Life in the middle of the metropolis gives birth to a climate of hedonism, where everyone feels happy with a life of spree and commitment. Many people unconsciously make hedonism the goal of life, like working nonstop to buy a luxury home. Many people do not realize that their pleasure in luxury homes is only a temporary pleasure. Once you get a luxury home, you have to go back to work to meet the needs of these luxury homes which are also expensive, such as taxes and maintenance. The desire in the climate of hedonism will continue to grow so that happiness is said to be only temporary happiness. Theme park can be interpreted as "reality substitute reality", which is an attempt to realize dreams. Everything is possible, so in the end the theme park criticizes the factors of visitors who are not as spectators but also as players. Animals are an attraction that is in great demand in this era because visitors can interact directly with living objects or can be said to be "two-way relations". Dogs are the closest animals and can interact directly with humans safely and pleasantly. Dogs are social beings like humans. Dogs have a unique position in relation to humans. The loyalty and dedication shown by dogs is very similar to the human concept of love and friendship. The closeness of dogs and humans makes dogs can be trained, invited to play, live with humans and socialize intensely with.
\end{abstract}

Keyword: hedonism, interact directly, reality

\section{PENDAHULUAN}

Jakarta merupakan Ibu Kota Negara yang dijadikan sebagai pusat kegiatan pemerintahan, perdagangan dan perekonomian, untuk itu Jakarta dikatakan sebagai kota metropolis. Kehidupan di tengah kota metropolis melahirkan sebuah iklim hedonisme, dimana setiap 
orangnya merasa bahagia dengan hidup berfoya-foya dan komsuntif. Banyak orang yang secara tidak sadar menjadikan hedonisme sebagai tujuan hidup, seperti bekerja tanpa henti demi membeli rumah mewah. Banyak orang tidak sadar bahwa kesenangan mereka akan rumah mewah hanyalah kesenangan yang sementara. Begitu mendapatkan rumah mewah, harus kembali bekerja untuk memenuhi kebutuhan rumah mewah tersebut yang juga mahal, seperti pajak dan perawatannya. Keinginan dalam iklim hedonisme akan terus bertambah sehingga dikatakan kebahagiaan yang di dapat hanyalah kebahagiaan sementara. Theme Park yang menampilkan visi kesenangan yang teratur dan terkendali meski seringkali menggunakan bentuk/wujud artistik yang cenderung menipu atau memperdaya merupakan suatu "pengganti" kenyataan demokrasi publik dan bahkan menjadi lebih menarik karena orang diberi "stimulasi" dan „simulasi" tentang keadaan yang lebih baik, dimana tidak ada kemiskinan, kecelakaan, kesenjangan sosial, kejahatan, sampah/limbah dan kondisi negatif urban lainnya karena seluruh komponen dalam lingkungan ini dapat dikontrol sesuai kondisi paling ideal yang diharapkan.

Program harus bersifat atraktif dan beragam agar pengunjung terhibur dan tidak bosan. Program juga harus aman untuk pengunjung, dimana tidak semua orang berani dengan anjing dan sifat anjing yang tidak bisa dikontrol seperti mesin atau memerlukan cara khusus untuk mengontrol anjing. Design bangunan bergaya fantasi, modern, penuh warna, unik, lucu, bebas, dan berani, hal ini agar memberikan kesan dan pengalaman arsitektur unik terhadap wisatawan. Lingkungan merupakan factor utama dalam program ini. Maka dari itu, dibutuhkan lingkungan yang asri dan nyaman. Factor kebersihan lingkungan juga sangat diutamakan mengingat akan ada bau yang pastinya akan timbul dari proyek ini. Lingkungan yang bersih akan mengundang orang untuk datang. Kebisingan juga akan timbul, akibat gonggongan anjing dan suara dari pendukung proyek. Alur sirkulasi merupakan hal penting dalam proyek, sirkulasi harus menimbulkan rasa 'penasaran' bagi pengunjung untuk terus ingin berkeliling dan melihat proyek sampai selesai. Maka dari itu, penyusunan ruang dan proses pembentukkan ruang merupakan hal yang harus ditinjau khusus.

Proyek diharapkan dapat menjadi daya tarik bagi wisatawan lokal maupun manca negara dengan program-program yang atraktif dan menciptakan pengalaman baru bagi pengunjung. Diharapkan juga, agar masyarakat sadar akan peranan hewan peliharaan yang sesungguhnya, yang sekarang ini sudah mulai memudar, yaitu hewan peliharaan sebagai teman bukan sesuatu objek yang hanya untuk dipamerkan.

\section{METODE}

Metode yang dilakukan selama melakukan penelitian adalah :

- Sumber dan Jenis Data: Data-data yang diperoleh dalam laporan ini berasal dari berbagai literatur kepustakaan yang berkaitan dengan permasalahan yang dibahas. Beberapa jenis referensi literature didapat dari buku dan sebagian didapat dari artikel online.

- Pengumpulan Data: Metode penulisan bersifat studi pustaka dan studi lapangan. Informasi didapatkan dari berbagai literatur dan survei lapangan yang didapatkan melalui observasi,. Penulisan diupayakan saling berkaitan satu sama lain dan sesuai dengan topik yang dibahas.

- Analisis Data: Data yang terkumpul diseleksi dan diurutkan sesuai dengan topik kajian. Kemudian dilakukan penyusunan karya tulis berdasarkan data yang telah dipersiapkan secara logis dan sistematis. Teknik analisis data bersifat deskriptif argumentatif.

- Penarikan Kesimpulan: Simpulan didapatkan setelah merujuk kembali pada tujuan penulisan serta pembahasan. Simpulan yang ditarik mempresentasikan pokok bahasan laporan, serta didukung dengan analisa studi kasus pembanding. 


\section{DISKUSI DAN HASIL}

\section{Kajian Teori}

Pariwisata dalam ruang metropolis memiliki tuntutan besar, dimana harus mencerminkan keseimbangan antara Architectural Tourism dan Tourism Architecture. Dengan kata lain, program yang diusulkan harus bisa menarik wisatawan dan juga dari segi arsitektur juga bisa menjadi objek dari pariwisata itu sendiri. Architourism dapat menjadi titi tolak dari ruang metropolis di berbagai bidang. Sebuah bangunan yang memiliki nilai arsitektur yang tinggi dapat menandakan kemakmuran, kemajuan teknologi, dan bahkan tingkat sosial masyarakat sebuah metropolis. Terutama bangunan yang memiliki pengakuan dunia, hal ini dapat menempatkan kota metropolis tersebut naik ke jajaran negara-negara maju yang juga memiliki nilai tinggi dalam aspek architourism, sekaligus dapat mengangkat nilai budaya dan berbagai sektor dalam ruang metropolis itu sendiri.

Taman Tematik merupakan sebuah tempat atau sarana hiburan yang memiliki ide dasar khusus yang mencirikan seluruh tempat rekreasi tersebut. Pengertian lain mengenai Taman Tematik (Theme Park) merupakan salah satu jenis taman yang memiliki karakteristik yang berbeda dari jenis taman lainnya. Karakteristik untuk setiap taman tematik tidaklah sama dengan taman tematik lainnya, karakteristik taman disesuaikan dengan tema taman yang digunakan.

Bangunan rekreasi harus dapat menampung berbagai macam aktifitas didalamnya. Bangunan/kawasan bertipe ini didesain untuk menampung kebutuhan berbagai jenis pengguna dan kebutuhannya. Daerah rekreasi juga harus menawarkan safe, healtful, serta attractive atmosphere. Bangunan rekreasi juga identik dengan kegiatan yang berhubungan/menyatu dengan keadaan lingkungan sekitar.

\section{Program kegiatan}

Berdasarkan kajian yang telah dilakukan, usulan desain yang diajukan untuk Architourism of the Metropolis adalah dengan membangun sebuah Taman Hiburan Tematik Dunia Anjing yang akan "membawa" pengunjung untuk memasuki dunia anjing dengan perancangan "rekayasa kota". Dimana program-program yang ada akan menjadi gambaran dari suasana kota dengan penduduk dan pelakunya adalah anjing.

\section{KESIMPULAN DAN SARAN}

Membuat sebuah Taman Hiburan Tematik Dunia Anjing akan mengurangi stress yang dialami masyarakat di iklim hedonisme ini.

Interaksi yang terjadi antara pengunjung dan Anjing dalam wisata ini akan menghasilkan hubungan 2 arah yang dapat menimbulkan sebuah kesan positif yang dirasakan oleh pengunjung dan dapat menjadi nilai moral tersendiri bagi pengunjung terhadap makhluk hidup terutama hewan peliharaan yang sering salahgunakan selama ini.

\section{REFERENSI}

Bruce Hayllar, Tony Griffin, Deborah Edwards. 2008. City Space. UK. Elvesvier Ltd.

Charles Montgomery. (2002). Happy City. UK

Drumm A dan Moore A. (2005). Ecotourism Development: A Manual for Conservation

Planners and Managers. Volume I: An Introduction to Ecotourism Planning (Second

Edition). Virginia. The Nature Conservancy.

Giuseppe Rossi dan Vujica M. .1994. Coping With Floods. London : Nato Scientific Affair Division

Holden A. (2000). Environment and Tourism. London. Rout-ledge.

Kraft, Patrick. (2005). Eco-Metropolis : Tourism of The Urban Ecology.Texas : UMI

Lang, Jon., (2005). Urban Design : A Typology of Procedurs and Products. Oxford : Routledge

Specth, Jan. (2014). Architecturl Tourism. Munich. SpringerGabler. 
https://www.theguardian.com/artanddesign/2017/oct/01/bilbao-effect-frank-gehryguggenheim-global-craze http://www.ecotourism.org/what-is-ecotourism https://www.researchgate.net/profile/Ferdinal_Asmin4/publication/323309174_Ekowisata_d an_Pembangunan_Berkelanjutan_Dimulai_dari_Konsep_Sederhana/links/5a8d482aaca272 92c0f8b87e/Ekowisata-dan-Pembangunan-Berkelanjutan-Dimulai-dari-KonsepSederhana.pdf?origin=publication_detail

https://www.archdaily.com/601048/big-designs-danish-recycling-center-as-neighborhoodasset

http://www.landezine.com/index.php/2014/07/beijiao-cultural-centre-by-gravity-partnershiplimited/

https://www.archdaily.com/782769/finnish-nature-center-haltia-lahdelma-and-mahlamaki 